\title{
Effects of Ecological Water Conveyance Project on the Structure, Species Diversity and Stability of Desert Riparian Forest in the Lower Reaches of Tarim River, Northwest China
}

\author{
Xiyi Wang \\ Taishan University \\ Tingting $\mathrm{Ma}$ \\ Taishan University \\ Hongbo Ling ( $\sim$ linghongbo0929@163.com ) \\ Xinjiang Institute of Ecology and Geography \\ Shuzhen Peng \\ Taishan University
}

Research

Keywords: Ecological stability, Diversity index, Ecological water conveyance, Structure of plant community, Lower reaches of Tarim river

Posted Date: December 16th, 2020

DOI: https://doi.org/10.21203/rs.3.rs-127475/v1

License: (c) (i) This work is licensed under a Creative Commons Attribution 4.0 International License.

Read Full License 


\section{Abstract}

Background: The lower reaches of the Tarim River is an arid region of inland China. In this area, vegetation is sparse and the environment is fragile. Therefore, it is of great significance to study the structure and stability of the plant community and ecosystem in the lower reaches of the Tarim River. It is valuable to increase the understanding of ecological protection and restoration in arid areas.

Methods: In this study, four sections, Yingsu, Karday, Alakan, and Yiganbjm, were selected as research sites, and 96 arbor and shrub quadrats and 288 herb quadrats were delimited in these sites. The ecological characteristics of all species in the quadrats were investigated. We selected the surveyed data from 2000, 2004, 2008, 2012, 2016, and 2019. Based on the data, we analyzed the variations in species composition. We also determined Shannon-Wiener indexes, Alatalo indexes, and ecological dominance to discuss the species diversity and uniformity of plant community. Plant community stability were also evaluated.

Results: There were 17 species in 2000 and 31 species in 2019. The proportion of arbor and shrub species decreased, while the understory herbaceous species gradually increased; all of the species become balanced. The stability of the plant community gradually increased; however, it remained unstable.

Conclusions: In general, water conveyance in an ecosystem plays a positive role in promoting the restoration of vegetation and ecological stability. This study provides a new method for the evaluation of ecological protection and restoration benefits in arid areas. Our findings can be a good reference for similar studies.

\section{Background}

Vegetation is a key component of ecosystems and plays an important role in ecological protection and control of desertification (Cédric et al. 2013). In recent decades, the economy has developed rapidly and the overall living standards of the human population have improved. However, some problems, such as ecological destruction, environmental degradation, and loss of biodiversity, have followed, posing a serious threat to the sustainable development of society (Barbier et al. 1996; Baranova et al. 2016). Arid areas, where water resources are limited, vegetation is sparse, and the environment is harsh, have become an area where a poor quality of life remains (Irajpoor and Latif. 2011). In recent years, poverty alleviation has been carried out in many regions, especially in China, which is the largest developing country (Qian 2019). General Secretary Jinping Xi proposed that "Lucid waters and lush mountains are invaluable assets," providing support for ecological protection and restoration, which can promote the development of the economy (Hasan et al. 2017). In view of the harsh natural environment and limited economic development in arid areas, it is necessary to conduct ecological protection and restoration projects in order to achieve a sustainable, stable, and coordinated development of the economy, society, and environment. 
Research and application of plant ecological theory is an important part of ecology (Illian et al. 2009). Whether in plains, plateaus, mountains, deserts, or river basins (Lortie and Turkington. 2002; Kirkman et al. 2012; Folega et al. 2014; Guo et al. 2018), composition of vegetation in these areas is closely related to the environmental factors (Espinar et al. 2011; Bayly et al. 2015; Noto and Shurin. 2017). However, structural characteristics of vegetation are affected by many factors and the processes by which vegetation changes is complex (Bertrand et al. 2011; Jacynthe et al. 2017; Estruch et al. 2018). As a result, it is necessary to study of vegetation structure. The characteristics of biodiversity is essential to understanding the relationships between biodiversity and ecological factors (Mahi et al. 2019). Vegetative species diversity is directly related to ecosystem function (Evans et al. 2017; Attarchi and Gloaguen 2018; Little and Altermatt 2018; Ricardo et al. 2019). However, it is unknown whether richness of species can improve the ecosystem function or if a certain number of key species can maintain the function (MacArthur 1955; Elton 1958; Lawton and Brown 1993), Therefore, studies on the change of species diversity can provide a theoretical basis for the evaluation of ecosystem functions, providing basic data for protection and restoration of biodiversity.

Community stability refers to the community's ability to maintain normal dynamics, including resistance stability and resilience stability (Gao et al. 2019). Stability of the plant community, which is one of the most important characteristics of the ecosystem, is a comprehensive feature of the structure and function of plant communities (Tomiolo et al. 2020). Different from simple mathematical or physical systems, ecosystems are complex and many problems require further study (Howeth and Leibold 2010). Studies of ecosystem stability generally require field investigations and data collection or the use of mathematical models to conduct a simulation (Schwartz et al. 2000; Neutel et al. 2014; Uroš et al., 2015; Zhang et al., 2017). However, these different approaches may lead to different conclusions and a more effective method is required. Zheng et al. (2000) proposed a new method where prediction results of community succession were with a comparative analysis.

In arid regions, water, which is the most important natural resource, has a great influence on characteristics of the plant community (Armas and Pugnaire. 2005; Wu et al. 2014; Wang et al. 2017). The lower reaches of the Tarim River is a typical arid region, and vegetation had been seriously degraded due to the river discontinuity before 2000. In this region, an ecological water conveyance project began in 2000. As a result, groundwater depth has increased, vegetative growth has improved, and plant diversity has increased (Aishan et al. 2015). With the implementation of the ecological water conveyance project, the density and coverage of species increased (Hao and Li. 2014). In addition, plant growth improved, the amount of water absorption increased, and transpiration increased (Ye et al. 2010), which led to an increase in the amount of ecological water needed for the growth of vegetation (Liu et al. 2014). However, previous research has only been conducted over short periods of time; the changes in the characteristics of vegetation in response to the ecological water conveyance project over the past 20 years have not been reported. In particular, studies on community stability are rare. We aimed to solve these problems in this study. The following hypothesises were made in this study: 
(1) Herbaceous species, which are the most sensitive to water conveyance, increased significantly. (2) Spatial pattern of species tended to be uniform. (3) Ecological water conveyance promoted an increase in community stability, which is currently stable.

Based on these hypothesises, we collected 20 years of monitoring data, including plant names, quantities, ecological characteristics (height, coverage, density), and distribution characteristics, to conduct calculations. The innovation of this study is to clarify the variations in plant community structure, species diversity, and community stability receiving ecological water conveyance, and to propose corresponding coping strategies. With the findings from this study, we can provide a theoretical basis for vegetation protection and restoration for ecological management projects conducted in the lower reaches of the Tarim River. We can also conduct a preliminary evaluation of the benefits of ecological water conveyance. In addition, the results of this study can provide a methodological reference for similar areas and theoretical guidance for the management of water resources in arid areas.

\section{Materials And Methods}

\section{Site description}

The total length of the lower reaches of the Tarim River, which refers to the reaches from the Daxihaizi reservoir to Taitema Lake $\left(86^{\circ} 37^{\prime} 23^{\prime \prime}-88^{\circ} 30^{\prime} 00^{\prime \prime} \mathrm{E}, 39^{\circ} 24^{\prime} 08^{\prime \prime}-41^{\circ} 03^{\prime} 40^{\prime \prime} \mathrm{N}\right)$, is $363 \mathrm{~km}$ (Zhang et al. 2004) (Fig. 1). The climate is temperate arid desert and the annual precipitation is approximately $20-50 \mathrm{~mm}$, while potential evaporation is up to 2,500-3,000 mm (Rumbaur et al. 2015). Because of resource exploitation occurring from the 1950 s to 1990 s, severe environmental problems drastically increased (Fu et al. 2008), including the discontinuous flow of the river channel, the disappearance of large areas of wetlands, significant decrease in groundwater depth, decline in areas of natural vegetation, and intensification of desertification (Liu et al. 2012). The proportion of the desertification area was greater $90 \%$, including an area of severe desertification accounting for $52.71 \%$ in 2000 (Mannisahan et al. 2009).

From 2000 to 2019, ecological water conveyance occurred 20 times in the lower reaches of the Tarim River. Due to the abundance of groundwater and river water, the vegetation cover increased and species diversity improved (Ling et al. 2020). A large area of arbor, shrub, and herb vegetation zones formed on the floodplain and along low terraces on both sides of the river channel (Mamat et al. 2019). The main arbor species was Populus euphratica. The shrub species included Tamarix chinensis, Lycium ruthenicum, and Halimodendron halodendron. Herbaceous species included Phragmites communis, Glossogyne tenuifolia, Alhagi sparsif, Karelinia capsica, and Halogeton glomeratus (Maierdang et al. 2018).

The total amount of water discharged 20 times exceeded $78 \times 10^{8} \mathrm{~m}^{3}$, with an average annual amount of $3.89 \times 10^{8} \mathrm{~m}^{3}$. The ecological water conveyance ended the continuous drying of the river channel that has occurred for nearly 30 years and the water head reached Taitema Lake 17 times. Groundwater has been effectively replenished on both sides of the river channel; therefore, the water environment has been 
improved significantly. According to the monitoring data from 2000 to 2019, the groundwater depth $1 \mathrm{~km}$ from the river channel ranged from 9.8-10.1 $\mathrm{m}$ to 1.1-3.3 $\mathrm{m}$. According to the monitoring data from the Chinese Academy of Sciences, the area of vegetation restoration and improvement was $2,285 \mathrm{~km}^{2}$, including an area of new vegetation of $362 \mathrm{~km}^{2}$ and the reduction of the area of sand to $854 \mathrm{~km}^{2}$. The area of Taitema Lake, which was once more than $510 \mathrm{~km}^{2}$, has contained water year-round, which led to the formation of wetlands $\left(223 \mathrm{~km}^{2}\right)$ around the lake.

\section{Vegetation surveys}

Researchers surveyed the vegetation in early to mid September every year. Investigations based on the fixed sections in the lower reaches of the Tarim River. Four typical sections, Yingsu, Karday, Alakan, and Yiganbjm, were selected as research sites. A monitoring transect was set up perpendicular to the river channel in every section. For this monitoring transect, large quadrats of $50 \mathrm{~m} \times 50 \mathrm{~m}$ were set up near the monitoring wells at distances of $50,150,300,500,750$, and $1,050 \mathrm{~m}$ from the river channel. In total, there were 24 fixed large quadrats that were set up in the region. For convenience, each large quadrat was divided into four smaller quadrats of $25 \mathrm{~m} \times 25 \mathrm{~m}$, then the individual number, coverage, DBH, height, and crown width of each arbor (or shrub) were recorded in these secondary quadrats. Three small herbal quadrats $(1 \mathrm{~m} \times 1 \mathrm{~m})$ were set up in each of the secondary quadrats, then the individual number, coverage, height, crown width, and frequency of each herb were recorded. Thus, 96 arbor and shrub quadrats and 288 herb quadrats were completed every year. In this study, we selected the data in 2000, 2004, 2008, 2012, 2016, and 2019.

\section{Importance value}

The importance value is the relative importance of different plant species in a community. Based on the measurement index of the importance value, the role of some small but numerous plant species can be avoided being exaggerated, that can provide an important basis to distinguish a species as an established species, a dominant species, or a companion species (Ramin et al. 2016). This measure was calculated following the method described by Hao et al. (2013).

\section{Diversity index, evenness index, ecological dominance}

The diversity index is an indicator of disorder and uncertainty among individuals of a species. The greater the uncertainty, the greater the diversity. The evenness index is an indicator of the distribution uniformity coefficient of species abundance (biomass, coverage, or other indicators). The increase of individual uniformity will also increase the diversity. Ecological dominance and the evenness index are opposite concepts. The higher the ecological dominance, the more uneven the distribution of species, and the more prominent species are considered the dominant species. The method by which this was calculated followed the description previously described by Gao et al. (2011).

\section{Characteristics of community stability}

Community stability was measured following the method provided by Godron (1972). Firstly, the measured frequency values of different species of plants in the community were arranged from large to 
small, and the frequency was converted to relative frequency, which was gradually accumulated from large to small in the order of relative frequency. Secondly, reciprocal of the sum of plant species were taken in the whole community, and gradually accumulate them according to the order of plant species, that obtain how many percentage of species occupy how much relative frequency of accumulation.

Thirdly, percentage of plant species corresponds to the cumulative relative frequency, and a scatter plot is drawn, and the points are connected with a smooth curve. Fourthly, a straight line is connected at the 100 scale of the two coordinate axes, and the intersection point with the curve is the desired point. The closer the ratio of species percentage to cumulative relative frequency is to $20 / 80$, the more stable the community will be. At $20 / 80$, it is the stable point of the community. However, the drawback to this method is that when the intersection coordinates of the smooth curve and the straight line need to be determined, it should be determined on grid paper. As a result, the coordinates may not be accurate; in addition, this method does not meet the current requirements of data automation. Therefore, in the process of drawing scatter plots and smooth curves, a mathematical model was established to simulate the smooth curve of a scatter graph following the methods described by Zheng (2000).

\section{Results}

From 2000 to 2019, with the implementation of ecological water conveyance, the number of plant families increased from eight to 12 , and number of species increased from 12 to 31 . (Table 1).

Table 1

Number of species to each family in different years

\begin{tabular}{|llllllll|}
\hline Serial number & Name of families & $\mathbf{2 0 0 0}$ & $\mathbf{2 0 0 4}$ & $\mathbf{2 0 0 8}$ & $\mathbf{2 0 1 2}$ & $\mathbf{2 0 1 6}$ & $\mathbf{2 0 1 9}$ \\
\hline 1 & Salicaceae & 1 & 1 & 1 & 1 & 1 & 1 \\
\hline 2 & Tamaricaceae & 1 & 1 & 1 & 1 & 1 & 1 \\
\hline 3 & Leguminosae & 3 & 3 & 3 & 4 & 3 & 4 \\
\hline 4 & Chenopodiaceae & 2 & 4 & 4 & 7 & 7 & 7 \\
\hline 5 & Amaranthaceae & 0 & 0 & 1 & 1 & 1 & 1 \\
\hline 7 & Compositae & 2 & 0 & 2 & 6 & 6 & 7 \\
\hline 8 & Cyperaceae & 0 & 0 & 1 & 3 & 3 & 3 \\
\hline 10 & Gramineae & 1 & 2 & 2 & 2 & 2 & 2 \\
\hline 11 & Apocynaceae & 1 & 1 & 1 & 1 & 1 & 1 \\
\hline 12 & Solanaceae & 1 & 1 & 1 & 1 & 1 & 1 \\
\hline 13 & Elaeagnaceae & 0 & 0 & 0 & 1 & 1 & 1 \\
\hline
\end{tabular}


With the implementation of ecological water conveyance, a large number of species appeared. However, these species are natives that existed decades ago, and reappeared due to water conveyance. According to Liu and Chen (2002), there was a dense of poplar forest that was 7-10 km wide and contained a large variety of plants in the lower reaches of the Tarim River. Since the lower Tarim River stopped flowing, there were few people, few animals, and almost no alien species. The ecological water conveyance project increased the number of species, vegetation area, and the ecosystem structure become more complicated.

\section{Changes of species composition in different biotopes}

Dominant species includes Populus euphratica, Tamarix chinensis, Alhagi sparsifolia, Phragmites australis, Apocynum venetum, and Karelinia caspia in the lower reaches of the Tarim River (Wang et al. 2019). Therefore, these species were selected to discuss the changes of plant community structure. We calculated the importance values of the abovementioned six dominant species. According to the different distances from the river channel, which correspond to the different groundwater depths, we divided the biotopes into six gradients, 50, 150, 300, 500, 750, and 1,050 m, from the river channel. For the four monitoring transects, the average value of vegetation characteristics on the same gradient was recorded as the vegetation characteristic value in this biotope. For example, for the entire area, vegetation characteristics at $50 \mathrm{~m}$ from the river channel are the average of vegetation characteristics at $50 \mathrm{~m}$ from the river channel at each of the transects. Importance values were used as the indicators to analyze the characteristics of change of the composition of the community structure in different biotopes since the beginning of the ecological water conveyance project.

As shown in Fig. 2, at different distances from river channel, the dominance of $P$. euphratica and $T$. chinensis decreased, but the proportion of the importance value still accounted for more than $50 \%$. The proportion of undergrowth herbs increased. In the area $50 \mathrm{~m}$ from the river, for example, the importance value of undergrowth herbs was only $16.12 \%$ in 2000 , but it reached to $26.93 \%$ in 2019 . In addition, with the increase of distance from the river, the proportion of $P$. euphratica and $T$. chinensis gradually increased, while the proportion of undergrowth herbs decreased gradually. In 2019, the proportion of $P$. euphratica and $T$. chinensis was $60.11 \%$, while the undergrowth herbs was $26.93 \%$ in the area $50 \mathrm{~m}$ from the river. However, in the area 1,050 $\mathrm{m}$ from the river, the proportion of $P$. euphratica and T. chinensis was $90.01 \%$, while the importance value of the undergrowth herbs was only $7.42 \%$. Beyond $500 \mathrm{~m}$ from the river channel, the proportion of undergrowth herbs was all below $15 \%$.

\section{Variation of species diversity in different biotopes}

For different water conditions, species diversity indexes (Shannon-Wiener indexes), evenness indexes (Alatalo indexes) and ecological dominances were used as indexes to analyze vegetation characteristics in different years. (Fig. 3).

The entire area was used as an example. Figure 2 shows that from 2000 to 2019 , both of the diversity indexes and evenness indexes showed an increasing trend. The average value of the Shannon-Wiener 
index was approximately 0.87 in 2000 and 1.75 in 2019. The average value of the Alatalo index was 0.61 in 2000 and 0.82 in 2019. These findings indicated that the number of species increased. However, ecological dominance was 0.32 , but it was 0.25 , indicating that the differences among the number, coverage, height, and other characteristics of each species decreased, and the distribution ratio of each species tended towards uniformity. However, in 2008, the evenness index reduced by 0.08 to it in 2004, but ecological dominance increased by 0.02 . Standard deviation of species diversity indexes, evenness indexes and ecological dominances were $0.55,0.16,0.07$. Therefore, there is a small gap between the values contained in each index, that is, the data results obtained in this experiment are more reasonable. These findings suggested that the distribution of species became uneven in 2008. Moreover, the highest values of diversity and evenness indexes, and the lowest values of ecological dominance all appeared at $150 \mathrm{~m}$, not $50 \mathrm{~m}$, from the river channel.

Vegetation in the upper reaches of the Tarim River was chosen as the reference. The upper and lower reaches of the Tarim River belong to the Tarim River basin, and the natural conditions between the two reaches of the river are relatively similar. The only difference is that the water resources in the upstream region are relatively abundant, which is beneficial to plant growth. In this comparison, the ShannonWiener index of the arbor-shrub community in the upstream and downstream were similar, indicating that the differences of arbor and shrub characteristics in the two regions were not significant and both were dominant. However, there were great difference in the Shannon-Wiener index between the two regions, which was similar to the research results presented by Zheng (2008). Overall, the impact of ecological water conveyance was more important on understory herbs.

\section{Characteristics of ecosystem stability}

Vegetation in four transects were synthesized as the example to discuss the characteristics of vegetation in the whole region. The stability of regional plant communities was evaluated by the measurement methods of community stability, and stability characteristics in different years were obtained (Fig. 4). According to Zheng (2000), when the distance between the intersection coordinate and the coordinates $(20,80)$ less than $=14.142$, the plant community is in a stable state, otherwise it is unstable.

Along with the implementation of ecological water conveyance, distances between intersection coordinates $(20,80)$ decreased gradually (Table 2$)$, suggesting that the ecological stability of plant community increased. However, it the plant community was still unstable in 2019. 
Table 2

Stability characteristics of plant community in different years in the lower reaches of Tarim river

\begin{tabular}{|llllll|}
\hline Year & curvilinear equation & $\mathbf{R}^{2}$ & $\begin{array}{l}\text { Intersection point } \\
\text { coordinate }\end{array}$ & $\begin{array}{l}\text { Distances } \\
\text { from } \\
(\mathbf{2 0 , 8 0 )}\end{array}$ & $\begin{array}{l}\text { Stability of } \\
\text { community }\end{array}$ \\
\hline 2000 & $\begin{array}{l}y=0.0014 x^{2}+0.8084 x+ \\
6.8981\end{array}$ & 0.9863 & $(48.58,51.42)$ & 40.42 & unstable \\
\hline 2004 & $\begin{array}{l}y=-0.0047 x^{2}+1.4824 x \\
+4.3054\end{array}$ & 0.9633 & $(41.87,58.13)$ & 30.93 & unstable \\
\hline 2008 & $\begin{array}{l}y=-0.0086 x^{2}+1.892 x- \\
2.5991\end{array}$ & 0.9741 & $(40.31,59.69)$ & 28.72 & unstable \\
\hline 2012 & $\begin{array}{l}y=-0.0126 x^{2}+2.2309 x \\
-0.522\end{array}$ & 0.9886 & $(36.23,63.77)$ & 22.95 & unstable \\
\hline $\begin{array}{l}y=-0.0133 x^{2}+2.2364 x \\
+4.8462\end{array}$ & 0.9886 & $(34.21,65.79)$ & 20.09 & unstable \\
\hline $\begin{array}{l}y=-0.0144 x^{2}+2.3076 x \\
+6.538\end{array}$ & 0.9813 & $(32.99,67.01)$ & 18.37 & unstable \\
\hline
\end{tabular}

\section{Discussion}

There were significant impacts of ecological water conveyance on the community structure of desert riparian forests, thus the diversity of species and stability of plant communities to some extent, supported our hypothesis. The proportions of arbors and shrubs decreased, while that of undergrowth herbs increased. In addition, as the number of species increased, the proportion of each species tended to be uniform. In other words, dominant species decreased. We also concluded that the stability of the plant community increased, but remained unstable at present. Therefore, the state and the government should continue to implement the ecological water conveyance project with reasonable measures to promote ecological protection and vegetation restoration.

\section{Effects of ecological water conveyance on community structure of desert riparian forest}

The growth, structure, and distribution of vegetation are closely related to the ecological environment, which affects the characteristics of vegetation, while the change of vegetation will react to the ecological environment (Xu et al. 2015). A basic feature of the plant community is the relationships between plant species, so as the relationships between plants and environment, which can be reflected by the configuration in spatial and temporal distribution of plant species. At present, studies of plant community are inseparable from the studies of community structure, and the importance value has been used widely (Hodabalo et al. 2013; Widodo, 2014). Therefore, it is feasible to discuss the changing characteristics of 
community structure by using importance values. Community structure is affected by many factors, such as climate, water, topography, and human activities (Kim et al. 2006; Collet et al. 2014; Leibowitz et al. 2018). Climate is dry in the lower reaches of the Tarim River, population is sparse, and the terrain is flat. Plant community structure is mainly affected by water conditions, which is related to ecological water conveyance. Ecological water conveyance caused the overflow of the river and the fluctuation of groundwater, leading to many effects on plant community structure (Chen et al. 2010). Groundwater was supplied by river water and groundwater depth increased, subsequently increasing the number, coverage, and height of species on the surface (Ling et al. 2015). This is consistent with the results of this study, which all indicated that ecological water conveyance played a positive role in promoting the growth and development of vegetation (Zencich et al. 2002; Thompson et al. 2011; Barbeta and Penuelas. 2017). Generally speaking, the changes in response to ground water observed were less obvious for plants with deep root systems than plants with shallow root systems. Specifically, herbs were more responsive to ground water levels than arbors and shrubs. Furthermore, ecological water conveyance caused river water to overflow, allowing seeds to germinate in the soil seed bank near the river channel. Moreover, seedlings grew rapidly. Therefore, the proportion of herbs near the river channel increased significantly, while the area distant from the river channel had fewer herbaceous species. The above findings also explained the results and verified the hypothesis of this study. On the whole, the height and coverage of arbors and herbs increased due to ecological water conveyance, but the increase was greater for herbs.

\section{Effects of ecological water conveyance on species diversity}

According to our results, both species diversity indexes and evenness indexes showed an increasing trend, while ecological dominance showed a decreasing trend on different distances from the river channel. Because the lower reaches of the Tarim River is very arid, water condition is an important factor to species diversity. More water was available due to ecological water conveyance, thus the number of species increased, the distribution and growth trend became uniform, and the ecological dominance of established species, such as $P$. euphratica and T. chinensis, decreased. This is also consistent with the results of this study. However, in 2008, diversity indexes and evenness indexes decreased and ecological dominance increased. This may be due to the a little water in 2007 and no water in 2008; therefore, during these 2 years, vegetation growth was slow and the area of plants with shallow roots reduced greatly, whereas the dominance of plants with deep roots, such as $P$. euphratica and $T$. chinensis, improved. We also found that it is not the better the water condition, the higher the species diversity index. In other words, values of these indexes were not positively correlated with the distances from the river channel. According to the groundwater depth and amount of overflow water, the water conditions were the most suitable for plant growth $50 \mathrm{~m}$ from the river channel. However, species diversity and uniformity were not the highest, and ecological dominance was not the lowest on this gradient. The highest values of species diversity indexes, evenness indexes, and the lowest values of ecological dominance all occurred at $150 \mathrm{~m}$ from the river channel. Based on this, a new question is raised: Are the results accurate? Hao et al. (2010) pointed out that the highest value of species diversity appeared at a groundwater depth of 2-4 $\mathrm{m}$, which corresponded to the 200-300 m from the river channel, not the area nearest the river channel. Bai et al. (2012) pointed out that the highest level of species diversity appeared at approximately $300 \mathrm{~m}$ from the 
river channel and showed that with the increase of the distances from the river channel, the diversity indexes and evenness indexes of species first increased and then decreased. Bai et al. (2016) found that highest value appeared at about 200-250 m from the river channel. However, with the implementation of ecological water conveyance in recent years, vegetation near the river channel has recovered, leading to the maximum value of species diversity being found closer to the river channel. There were favorable supports of above arguments to the results of this study. We concluded that the maximum value of species diversity and evenness of the plant community was at a distance of $150 \mathrm{~m}$ from the river channel, which may be related to the availability of appropriate water conditions for plant growth. The groundwater depth at $150 \mathrm{~m}$ from the river channel is needed for plant growth, that growth of plant community, which with high species diversity and uniformity, was in good condition.

\section{Relationship between community stability and ecological water conveyance}

The improvements of Godron's method, which was comprehensive and systematic, were based on the overall characteristics of community. This method can be applied on various arbors, shrubs, and herbs, as well as provide information on community stability, the direction of succession, and the trend in the community (Lu et al. 2018). Therefore, this method, which was suitable, was helpful to understand the dynamic changes within the community. In this study, mathematical simulation was added to improve the method, promoting Godron's method as quantitative and reliable, and the method became easier to conduct. Therefore, the results of this study are of high accuracy. In the future, the model simulation should be more accurate and advanced calculation methods should be used to improve the accuracy of the results. Research on the community stability in the lower reaches of the Tarim River has not yet been studied. As a result, there were still many defects in the evaluation of the ecological water conveyance project. It is necessary to evaluate the community stability of desert riparian forests in the lower reaches of the Tarim River and propose scientific countermeasures for the ecological water conveyance project. We conclude that due to the ecological water conveyance, community stability has been increased, which also indicated that the ecological water conveyance project was beneficial. However, the community is still unstable state, which contradicted our third hypothesis. Therefore, the ecological water conveyance project needs to be conducted continuously to promote the stability and sustainability of regional plant community structure. Different regions had different vegetation characteristics, such as the distribution range and growth (Sun et al. 2017); therefore, implementation of ecological water conveyance should be conducted according to the physiological and ecological characteristics of plants in different regions. In the lower reaches of the Tarim River, water conveyance mainly promotes the recovery of asexual reproduction of plants via root tillers. In addition, reproduction via seed germination mainly appeared in the areas with river overflow, which was affected by microtopography. However, both modes of reproduction are restricted in extremely degraded areas. To achieve a wider range of vegetation restoration, we recommend that different restoration measures should be implemented in different river sections. In the areas with good plant growth, the current mode of ecological water conveyance should be continue to develop. In the areas of middle degradation, artificial surface overflows should be carry out to

Page $11 / 22$ 
promote seed germination. In the areas of extreme degradation, the amount of water resources should be reduced and manual reseeding measures should be taken.

In general, the lower reaches of the Tarim River is sparsely populated and rural, with the industries mainly animal husbandry and farming. With the implementation of the ecological water conveyance project, ecology in the region began to recover and the environment improved. For a long time, people's traditional understanding of ecological restoration mode mainly lies in ecological water conveyance. However, the lower reaches of the Tarim River is a very dry area. Is it reasonable to promote vegetation restoration only by river channel water conveyance from an abundant water resource? Does ecosystem restoration in the lower reaches of the Tarim River meet its historical goals? Therefore, we need to re-evaluate the current novel ecosystem to set multiple goals for its management (Hobbs et al. 2013). Thus, we must acknowledge that novel ecosystems do not necessarily pose a threat to existing policies and management practices; instead, we must develop a new management method that can manage the current status of the rapidly changing ecosystem (Hobbs et al. 2014). Therefore, a new understanding of novel ecosystems in the lower reaches of the Tarim River can enable managers to consider ecological restoration methods more comprehensively and make more effective decisions based on ecosystem changes.

\section{Conclusion}

This study explained important and complex influences of ecological water conveyance on the characteristics of vegetation community in the lower reaches of the Tarim River, which may feed back to the environment and interfere the quality of the environment. Community structure, species diversity, and community stability all responded to ecological water conveyance. In general, with the implementation of the ecological water conveyance project, the proportion of arbors and shrubs decreased, the proportion of undergrowth herbs increased, and the distribution of species tended to be uniform. The stability of the community also increased, but it remained in an unstable state. Therefore, in the future, it is necessary to update the modes of ecological water conveyance, and the duration of annual water conveyance should coincide with the growing period of plants and the season in which seeds germinate to make full use of the water resources. Attention should be paid to the long-term monitoring of changes in plant ecosystems to clarify the interaction between the environment and ecological water conveyance in arid areas.

\section{Declarations}

\section{Acknowledgements}

This paper was supported by the the Science and Technology Service Network Project of Chinese Academy of Sciences (KFJ-STSQYZD-114), the West Light Foundation of Chinese Academy of Sciences (2019-XBQNXZ-A-001), and Doctoral Research Initiation Foundation of Taishan University in Shandong, China (Y-02-2018012). The authors would like to express their cordial gratitude for assistance in this 
research to Hailiang Xu, Guangpeng Zhang in Xinjiang Institute of Ecology and Geography, Chinese Academy of Sciences, Urumqi, China.

\section{Author Contributions}

Conceptualization and methodology, X.W. and H.L.; writing-original draft preparation, X.W.; supervision and data analysis, X.W. and S.P.; project administration and funding, H.L.; data processing, X.W. and T.M.

\section{Fundings}

This paper was supported by the the Science and Technology Service Network Project of Chinese Academy of Sciences (KFJ-STSQYZD-114), the West Light Foundation of Chinese Academy of Sciences (2019-XBQNXZ-A-001).

\section{Availability of data and materials}

Not applicable.

\section{Ethics approval and consent to participate}

Not applicable.

\section{Consent for publication}

Not applicable.

\section{Competing interests}

The authors declare that they have no competing interests.

\section{Author details}

${ }^{1}$ Department Taishan University, Taian, Shandong, 271000, China.

${ }^{2}$ Xinjiang Institute of Ecology and Geography, Chinese Academy of Sciences, Urumqi, Xinjiang 830011, China.

\section{References}

1. Aishan T, Halik U, Kurban A, Cyffka B, Kuba M, Betz F, Keyimu M (2015) Eco-morphological response of floodplain forests (Populus euphratica Oliv.) to water diversion in the lower Tarim River, northwest China. Environmental Earth Sciences, 73:533-545

2. Armas C, Pugnaire FI (2005) Plant interactions govern population dynamics in a semi-arid plant community. Journal of Ecology, 93:978-989 
3. Attarchi S, Gloaguen R (2018) A multi-sensor approach for improving biodiversity estimation in the Hyrcanian mountain forest, Iran. International Journal of Remote Sensing, 39:7311-7327

4. Bai Y, Xu HL, Zhang P, Zhao XF, Fu JY (2012) Species Diversity and Structural Characters of Desert Plant Communities in Lower Reaches of Tarim River. Journal of Ecology and Rural Environment, 28:16-22 (in Chinese)

5. Bai YF, Chen CQ, Xu HL, Zhang GP, Zhang P, Ling HB (2016) Relationship between Spatial Distribution of Aboveground Biomass of Desert Vegetation and Groundwater Depth in the Lower Reaches of Tarim River, Xinjiang,China. Scientia Silvae Sinicae, 52:1-10 (in Chinese)

6. Baranova A, Schickhoff U, Wang SL, Jin M (2016) Mountain pastures of Qilian Shan: plant communities, grazing impact and degradation status (Gansu province, NW China). Hacquetia, 15:2135

7. Barbeta A, Penuelas J (2017) Relative contribution of groundwater to plant transpiration estimated with stable isotopes. Scientific Reports, 7:10580

8. Barbier EB, Stern DI, Common MS (1996) Economic Growth and Environmental Degradation: The Environmental Kuznets Curve and Sustainable Development. World Development, 24:1151-1160

9. Bayly MJ, Pollock LJ, Vesk PA (2015) The Roles of Ecological and Evolutionary Processes in Plant Community Assembly: The Environment, Hybridization, and Introgression Influence Co-occurrence of Eucalyptus. American Naturalist, 185:784-796

10. Bertrand R, Lenoir J, Piedallu C, Gabriela RD, Patrice DR, Claude V, Pierrat JC, Gegout JC (2011) Changes in plant community composition lag behind climate warming in lowland forests. Nature, 479:517-520

11. Cédric FD, Shipley B, Meziane D, Yves H (2013) Trait-based climate change predictions of plant community structure in arid steppes. Journal of Ecology, 101:484-492

12. Chen YN, Chen YP, Xu CC, Ye ZX, Li ZQ, Zhu CG, Ma XD (2010) Effects of ecological water conveyance on groundwater dynamics and riparian vegetation in the lower reaches of Tarim River, China. Hydrological Processes, 24:170-177

13. Collet L, Ruelland D, Borrell EV, Servat E (2014) Assessing the long-term impact of climatic variability and human activities on the water resources of a meso-scale Mediterranean catchment. International Association of Scientific Hydrology Bulletin, 59:1457-1469

14. Elton CS (1958) The ecology of invasions by animal and plants. London: Chapman and Hall, 143153

15. Espinar JL, Ross MS, Sah JP (2011) Pattern of nutrient availability and plant community assemblage in Everglades Tree Islands, Florida, USA. Hydrobiologia, 667:89-99

16. Estruch C, Lozana YM, Armas C, Pugnaire FI (2018) Plant community changes after land abandonment control $\mathrm{CO} 2$ balance in a dry environment. Plant \& Soil, 425:1-12

17. Evans PM, Newton AC, Cantarello E, Martin P, Sanderson N, Jones DL, Barsoum N, Cottrell JE, A'hara SW, Fuller $L$ (2017) Thresholds of biodiversity and ecosystem function in a forest ecosystem undergoing dieback. Scientific Reports, 7:6775 
18. Folega F, Zhang CY, Woegan YA, Kperkouma W, Marra D, Batawila K, Seburanga JK, Zhao XH, Akpagana K (2014) Structure and ecology of forest plant community in Togo. Journal of Tropical Forest Science, 26:225-239

19. Fu AH, Chen YN, Li WH. (2008) Change on Water Potential of Differently Shaped Leaves in Populus euphratica in Lower Reaches of Tarim River, Xinjiang. Journal of Desert Research, 83-88. (In chinese)

20. Gao X, Huang PT, Wang K (2019) Assessment of the ecosystem stability of Shapotou Arid Desert Nature Reserve in Ningxia, China. 2019, 39: 6381-6392. (In chinese)

21. Gao YN, Gao JF, Chen JF, Xu Y, Zhao JH (2011) Regionalizing Aquatic Ecosystems Based on the River Subbasin Taxonomy Concept and Spatial Clustering Techniques. International Journal of Environmental Research and Public Health, 8:4367-4385

22. Godron MS (1972) Some aspects of het erogeneity in grasslands of C antal.Statistical Ecology ,3:397

23. Guo L, Chen J, Luedeling E, He JS, Cheng JM, Wen ZM, Peng CH (2018) Early-spring soil warming partially offsets the enhancement of alpine grassland aboveground productivity induced by warmer growing seasons on the Qinghai-Tibetan Plateau. Plant and Soil, 425:177-188

24. Hao XM, Li WH (2014) Impacts of ecological water conveyance on groundwater dynamics and vegetation recovery in the lower reaches of the Tarim River in northwest China. Environmental Monitoring \& Assessment, 186:7605-7616

25. Hao XM, Li WH, Guo B, Ma JX (2013) Simulation of the effect of root distribution on hydraulic redistribution in a desert riparian forest. Ecological Research, 28:653-662

26. Hao XM, Li WH, Huang X, Zhu CG, Ma JX (2010) Assessment of the groundwater threshold of desert riparian forest vegetation along the middle and lower reaches of the Tarim River, China. Hydrological Processes, 24:178-186

27. Hasan S, Deng XZ, Li ZH, Chen DD (2017) Projections of Future Land Use in Bangladesh under the Background of Baseline, Ecological Protection and Economic Development. Sustainability, 17:505

28. Hobbs RJ, Higgs E, Hall CM, Bridgewater P, Chapin FS, Ellis EC, Ewel JJ, Hallett LM, Harris J, Hulvey KB, Jackson ST, Kennedy PL, Kueffer C, Lach L, Lantz TC, Lugo AE, Mascaro J, Murphy SD, Nelson CR, Perring MP, Richardson DM, Seastedt TR, Standish RJ, Starzomski BM, Suding KN, Tognetti PM, Yakob L, Yung L (2014) Managing the whole landscape: historical,hybrid, and novel ecosystems. Frontiers in Ecology and the Environment, 12:557-564

29. Hobbs RJ, Higgs ES, Hall CM (2013) Novel Ecosystems: Intervening in the New Ecological World Order. Restoration Ecology, 21:523-525

30. Hodabalo P, Kperkouma W, Thomas TC Michael PBB, Zida M, Marra D, Komlan B, Koffi A (2013) Woody species diversity and important value indices in dense dry forests in Abdoulaye Wildlife Reserve (Togo, West Africa). International Journal of Biodiversity and Conservation, 5:358-366

31. Howeth JG, Leibold MA (2010) Species dispersal rates alter diversity and ecosystem stability in pond metacommunities. Ecology, 91:27-41 
32. Illian JB, M?Iler J, Waagepetersen RP (2009) Hierarchical spatial point process analysis for a plant community with high biodiversity. Environmental \& Ecological Statistics, 16:389-405

33. Irajpoor AA, Latif M (2011) Performance of irrigation projects and their impacts on poverty reduction and its empowerment in arid environment. International Journal of Environmental Science \& Technology, 8:533-544

34. Jacynthe M, Prescott CE, Renaut S, Terrat Y, Grayston SJ (2017) Plant community and nitrogen deposition as drivers of $a$ - and $\beta$-prokaryotic diversity in reconstructed oil-sands soils and natural boreal forest soils. Applied and Environmental Microbiology, 83(9): e03319-16

35. Kim ES, Dong KP, Zhao XY, Hong SK, Kang SK, Min HS, Kim YS (2006) Sustainable management of grassland ecosystems for controlling Asian dusts and desertification in Asian continent and a suggestion of Eco-Village study in China. Ecological Research, 21:907-911

36. Kirkman LK, Goebel PC, West L, Drew MB, Palik BJ (2012) Depressional Wetland Vegetation Types: A Question of Plant Community Development. Wetlands, 20:373-385

37. Lawton JH, Brown VK (1993) Redundancy in ecosystems. In: Biodiversity and Ecosystem Function (eds Schulze ED, Mooney HA). Springer, New York

38. Leibowitz SG, Wigington PJ, Schofield KA, Alexander LC, Vanderhoof MK, Golden HE (2018) Connectivity of Streams and Wetlands to Downstream Waters: An Integrated Systems Framework. Jawra Journal of the American Water Resources Association, 54:1-25

39. Ling HB, Guo B, Yan JJ, Deng XY, Xu HL, Zhang GP (2020) Enhancing the positive effects of ecological water conservancy engineering on desert riparian forest growth in an arid basin. Ecological Indicators, 118:106797

40. Ling HB, Zhang P, Xu HL, Zhao XF (2015) How to Regenerate and Protect Desert Riparian Populus euphratica Forest in Arid Areas. Scientific Reports, 5:15418

41. Little CJ, Altermatt $F$ (2018) Species turnover and invasion of dominant freshwater invertebrates alter biodiversity-ecosystem function relationship. Ecological Monographs, 88: 461-480

42. Liu GL, Kurban A, Duan HM, Umut H, Abdimijit A, Zhang LC (2014) Desert riparian forest colonization in the lower reaches of Tarim River based on remote sensing analysis. Environmental Earth Sciences, 71:4579-4589

43. Liu JZ, Chen YN. (2002) Analysis on converse succession of plant communities at the lower reaches of Tarim river. Arid Land Geography, 25: 231-236.

44. Liu XH, Xu HL, Ling HB, Zhang P, Dai Y, Bai Y. (2012) Spatio-temporal Variations of Soil Water and Salinity in Drip Irrigation Shelterbelt in a Typical Oasis in the Lower Reaches of the Tarim River. Journal of Desert Research, 6: 1604-1610. (In chinese)

45. Lortie CJ, Turkington R (2002) The effect of initial seed density on the structure of a desert plant community. Journal of Ecology, 90:435-445

46. Lu LL, Guo ZL, Fan CN, Zheng JP (2018) Community characteristics and stability analysis of secondary deciduous broad-leaved forest in Mopan Mountains, Jilin Province, China. Chinese Journal of Applied Ecology, 29:2079-2087 (In chinese) 
47. MacArthur R (1955) Fluctuations of animal populations, and a measure of community stability. Ecology, 36:533-536.

48. Mahi A, Lorenzo TD, Haicha B, Belaidi N, Taleb A (2019) Environmental factors determining regional biodiversity patterns of groundwater fauna in semi-arid aquifers of northwest Algeria. Limnology, 20:309-320

49. Maierdang K, Mut $\mathrm{H}$, Florian $\mathrm{B}$, Choimaa $\mathrm{D}$ (2018) Vitality variation and population structure of a riparian forest in the lower reaches of the Tarim River, NW China. Journal of Forestry Research, 3 : 749-760.

50. Mamat Z , Halik U , Aishan T , Aini A, Hepp LU. (2019) Ecological effect of the riparian ecosystem in the lower reaches of the Tarim River in northwest China. PLoS ONE, 14: e0208462.

51. Mannisahan T, Tuersun H, Huang GH, Shi L. (2009) Desertification Disasters and Its Control Countermeasures in the Oasis of the Lower Reaches of Tarim River. Xinjiang Agricultural sciences, 46: 380-387. (in Chinese)

52. Neutel AM, Thorne MAS, Adler F (2014) Interaction strengths in balanced carbon cycles and the absence of a relation between ecosystem complexity and stability. Ecology Letters, 17:651-661

53. Noto AE, Shurin JB (2017) Mean conditions predict salt marsh plant community diversity and stability better than environmental variability. Oikos, 126:1308-1318

54. Qian JW (2019) Rural Poverty Alleviation in China: Recent Reforms and Challenges. East Asian Policy, 08:82-90

55. Ramin H, Javad S, Vahid A, Sheyda K, Hamdieh K. (2016) Diversity of woody plant species and their relationship to physiographic factors in central Zagros forests (Case study: Perc forest, Khorramabad, Iran). Journal of forestry research, 27:1137-1141

56. Ricardo RE, Estrada CG, Alvarez CST, Yarelys FS (2019) Comparing individual raptor species and coarse taxonomic groups as biodiversity surrogates in desert ecosystems. Biodiversity and Conservation, 28:1225-1244

57. Rumbaur C, Thevs N, Disse M, Ahlheim M, Brieden A, Cyffka B, Doluschitz R, Duethmann D, Feike T, Fror O, Gartner P, Halik U, Hill J, Hinnenthal M, Keilholz P, Kleinschmit B, Krysanova V, Kuba M, Mader S, Menz C, Othmanli H, Pelz S, Schroeder M, Siew TF, Stender V, Stahr K, Thomas FM, Welp M, Wortmann M, Zhao XN, Chen XG, Jiang TQ, Zhao CY, Zhang XR, Luo J, Yimit H, Yu RD (2015) Sustainable management of river oases along the Tarim River (SuMaRiO) in Northwest China under conditions of climate change. Earth System Dynamics Discussions, 6:83-107

58. Schwartz MW, Brigham CA, Hoeksema JD, Lyons KG, Mills MH, Mantgem PJ (2000) Linking biodiversity to ecosystem function: implications for conservation ecology. Oecologia, 122:297-305

59. Sun AZ, Guo ZT, Wu HB, Li Q, Yu YY, Luo YL, Jiang WY, Li XQ (2017) Reconstruction of the vegetation distribution of different topographic units of the Chinese Loess Plateau during the Holocene. Quaternary Science Reviews, 173:236-247

60. Thompson SE, Harman CJ, Konings AG, Sivapalan M, Neal A, Troch PA (2011) Comparative hydrology across AmeriFlux sites: The variable roles of climate, vegetation, and groundwater. Water 
Resources Research, 47:1-7

61. Tomiolo S, Bilton MC, Tielbrger K (2020) Plant community stability results from shifts in species assemblages following whole community transplants across climates. Oikos, 129:70-80

62. Uroš R, Miloš N, Jelena M (2015) Identification of Marginal Land Suitable For Biofuel Production In Serbia. Acta Regionalia Et Environmentalica, 12:51-55

63. Wang J, Fu BJ, Lu N, Zhang L (2017) Seasonal variation in water uptake patterns of three plant species based on stable isotopes in the semi-arid Loess Plateau. Science of the Total Environment, 609:27-37

64. Wang XY, Ling HB, Xu HL, Pan CD, Yuan KY (2019) Relationships between Plant Communities and Environmental Factors in an Extremely Arid Area: A Case Study in China. Polish Journal of Environmental Studies, 28:359-370

65. Widodo W (2014) Composition and important value index of birds in relation to study of bali starling (leucopsar rothschildi) in the bali barat national park. Scandinavian Journal of Economics, 109:883903

66. Wu GL, Zhang ZN, Wang D, Shi ZH, Zhu YJ (2014) Interactions of soil water content heterogeneity and species diversity patterns in semi-arid steppes on the Loess Plateau of China. Journal of Hydrology, 519:1362-1367

67. Xu J, An YL, Hu F, Ma LR (2015) Research on characteristics of ecological environment in a semikarst region based on vegetation cover and NPP: A case study in central Guizhou province. Geographical Research, 34: 644-654. (in Chinese)

68. Ye ZX, Chen YN, Li WH (2010) Ecological water demand of natural vegetation in the lower Tarim River. Journal of Geographical Sciences, 20:261-272

69. Zencich SJ, Froend RH, Gailitis TV (2002) Influence of groundwater depth on the seasonal sources of water accessed by Banksia tree species on a shallow, sandy coastal aquifer. Oecologia, 131:8-19

70. Zhang YH, Michel L, He NP, Zhang GM, Han XG (2017) Mowing exacerbates the loss of ecosystem stability under nitrogen enrichment in a temperate grassland. Functional Ecology, 31:1637-1646

71. Zhang YM, Chen YN, Zhang XL. (2004) Plant Communities and Their Interrelations with Environmental Factors in the Lower Reaches of Tarim River. Acta Geographica Sinica, 59: 903-910. (in Chinese)

72. Zheng Y. (2008) Comparative Analysis on Plant Community Characteristics in the Upper and Lower Reaches of Trim River. Journal of Arid Land Resources and Environment, 22, 152-156. (in Chinese)

73. Zheng YR (2000) Comparison of methods for studying stability of forest community. Scientia silvae sinicae, 36:28-32 (in Chinese)

\section{Figures}




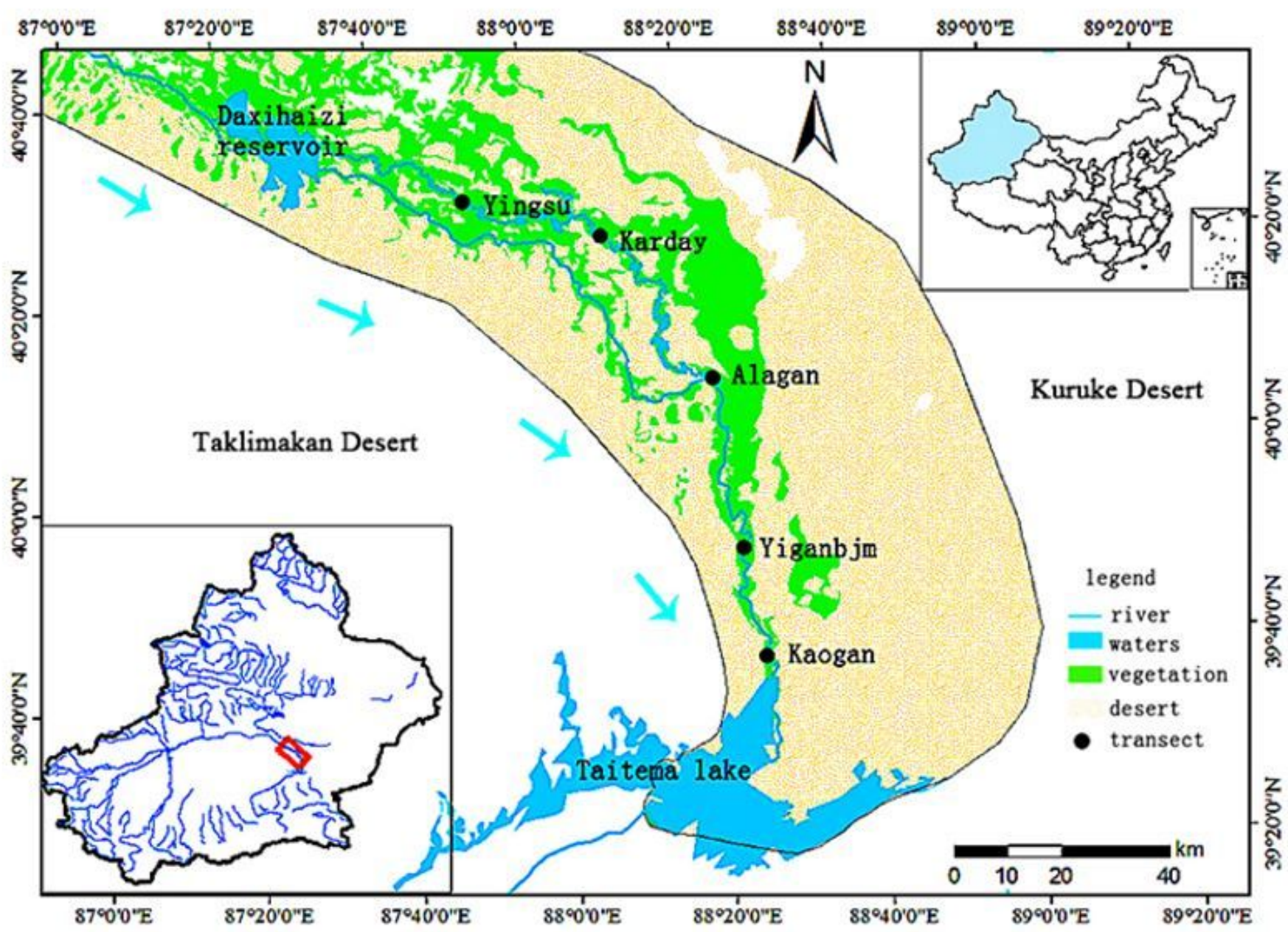

Figure 1

Sketch map of the low reaches of Tarim river Note: The designations employed and the presentation of the material on this map do not imply the expression of any opinion whatsoever on the part of Research Square concerning the legal status of any country, territory, city or area or of its authorities, or concerning the delimitation of its frontiers or boundaries. This map has been provided by the authors. 


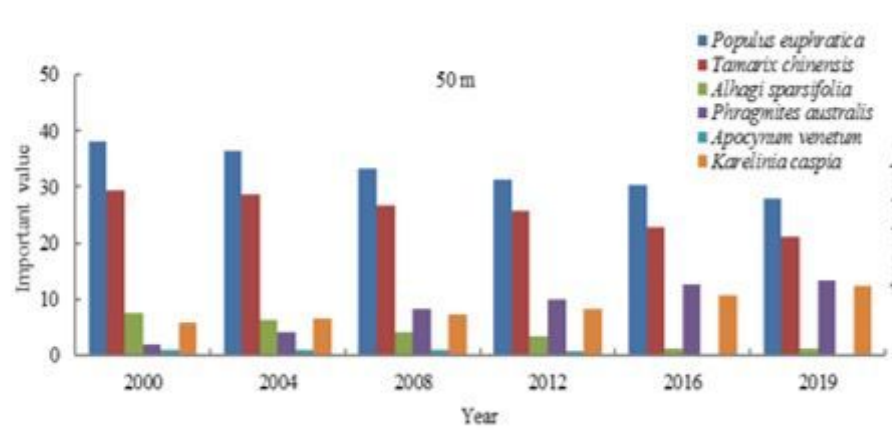

a

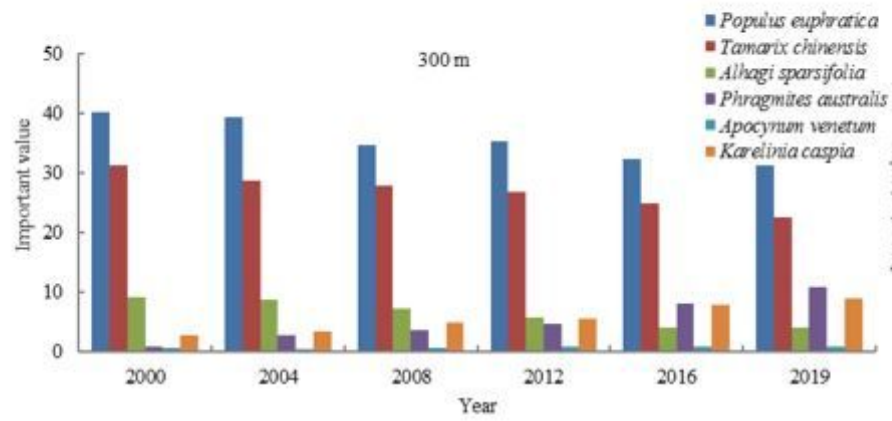

$\mathrm{c}$

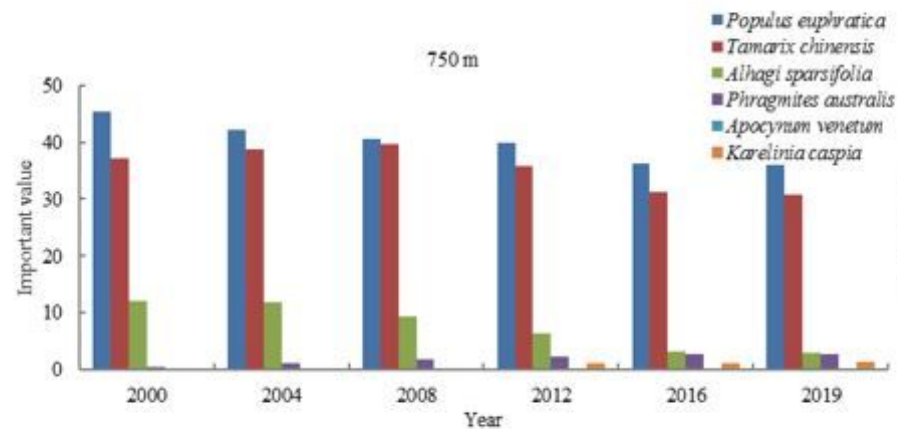

e

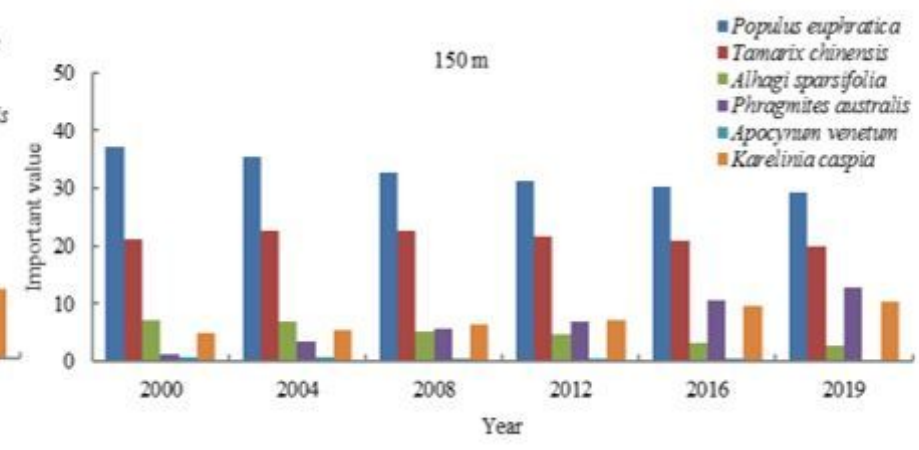

b

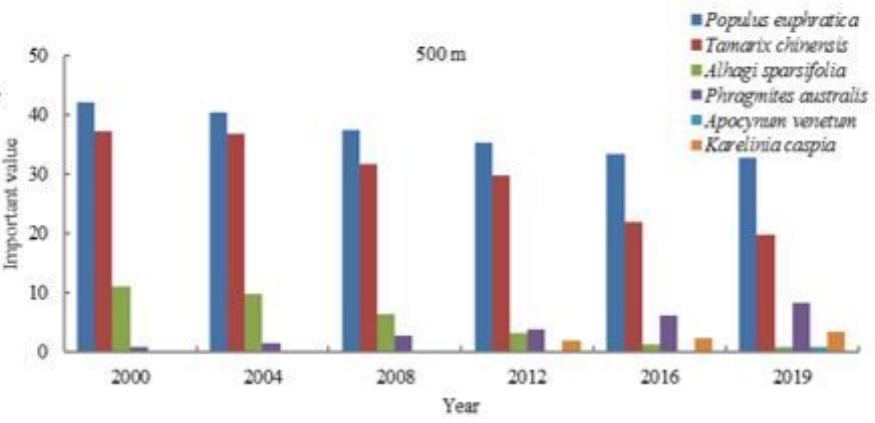

d

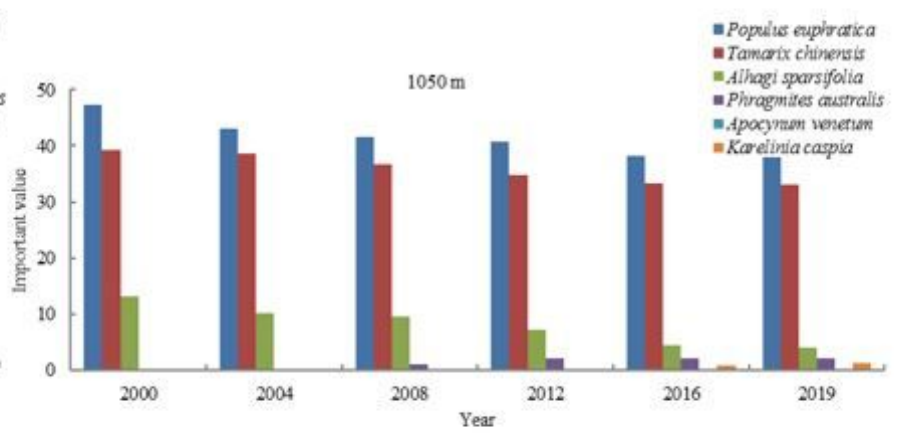

f

Figure 2

Important value characteristics of dominant species on different distances from river channel in different years 


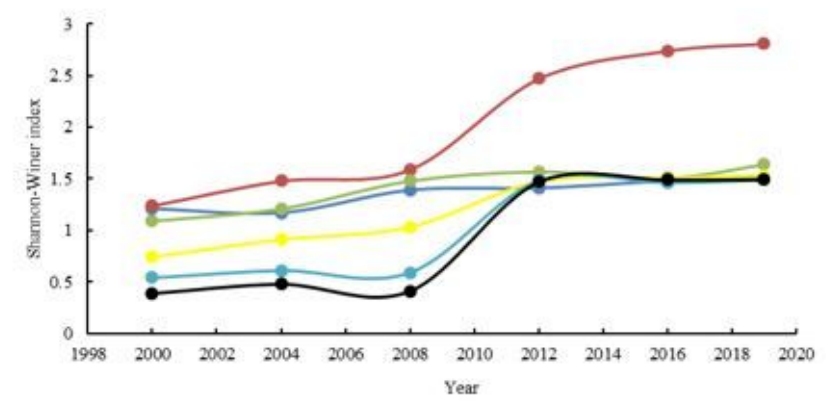

a
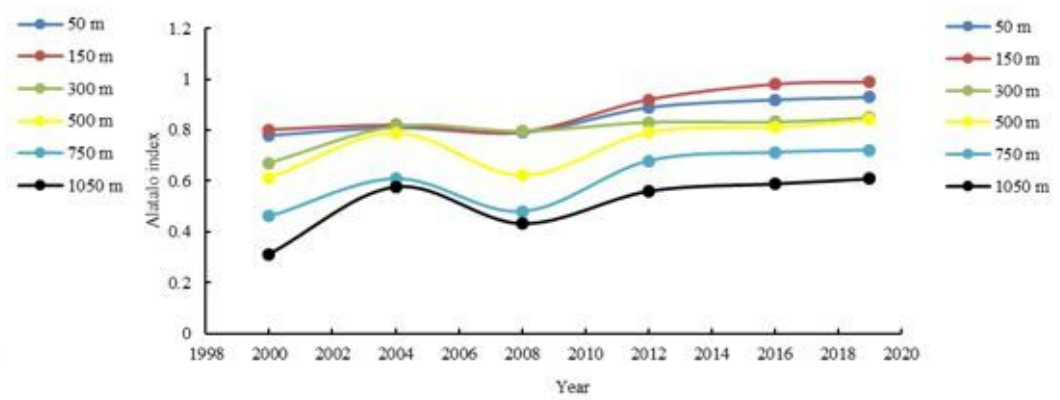

b

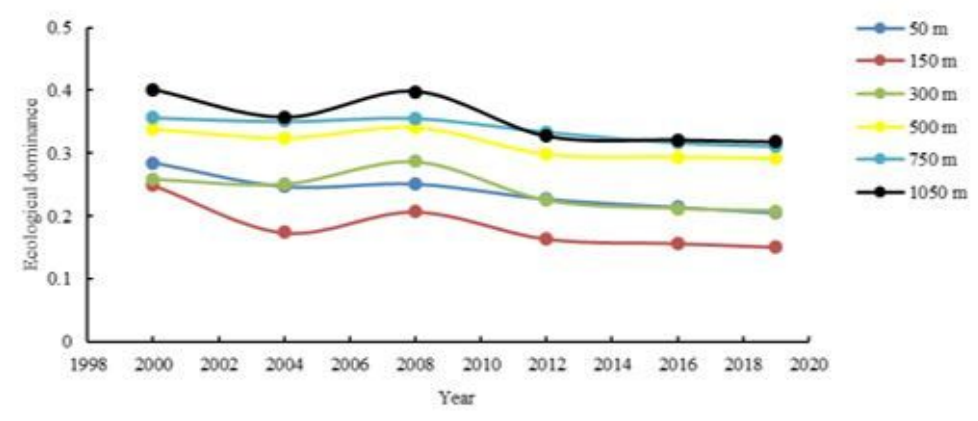

c

\section{Figure 3}

Variation characteristics of Shannon-Wiener indexes, Alatalo indexes and ecological dominances in different distances from river $₫$ Notes: 50 m, 150 m, 300 m, 500 m, 750 m, 1050 m represent the biotope that $50 \mathrm{~m}, 150 \mathrm{~m}, 300 \mathrm{~m}, 500 \mathrm{~m}, 750 \mathrm{~m}, 1050 \mathrm{~m}$ distances from the river channel respectively.) 


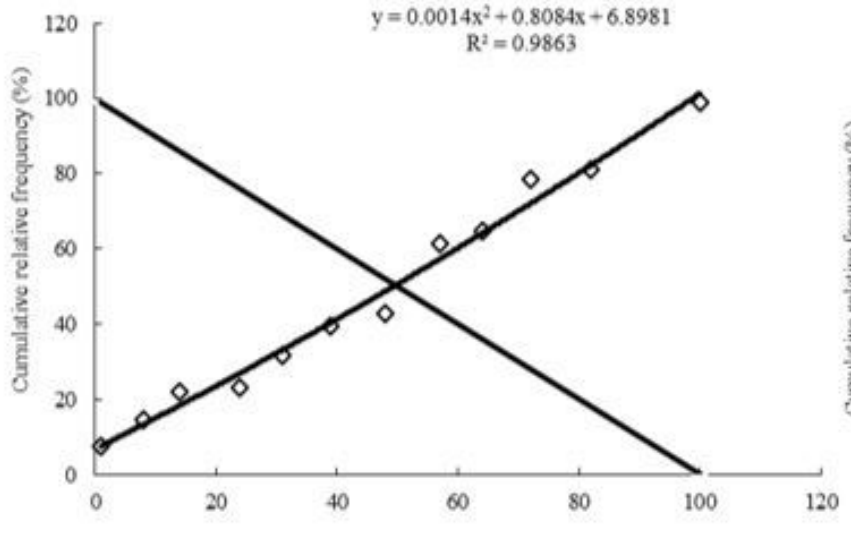

Reciprocal accumulation of total number of species (\%)

2000

a

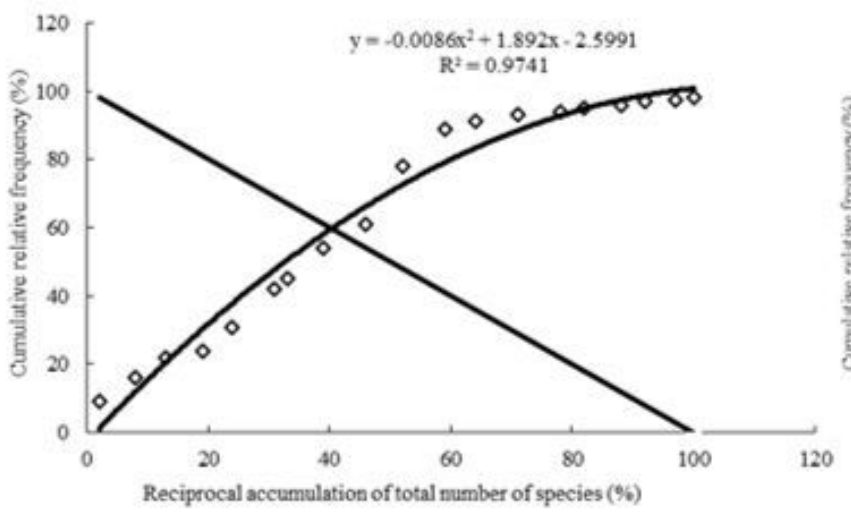

2008

c

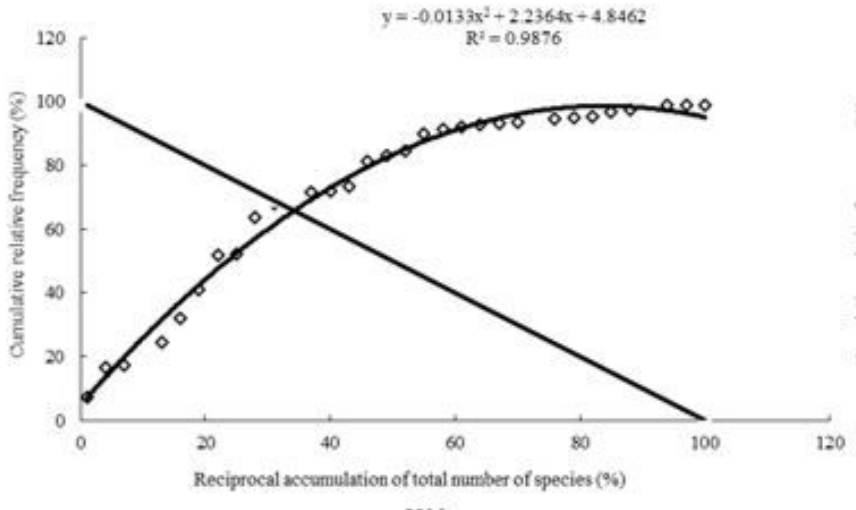

2016

e

\section{Figure 4}

Stability of plant community in different years

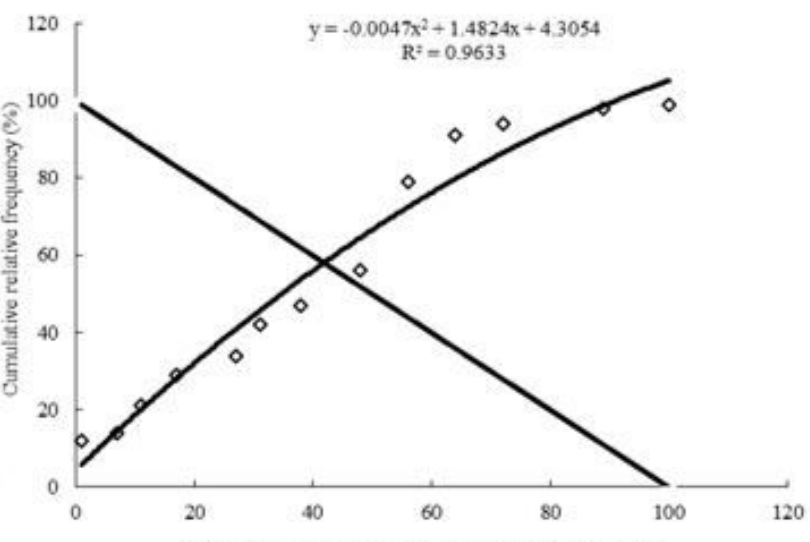

Reciprocal accumulation of total number of species (\%)

2004

b

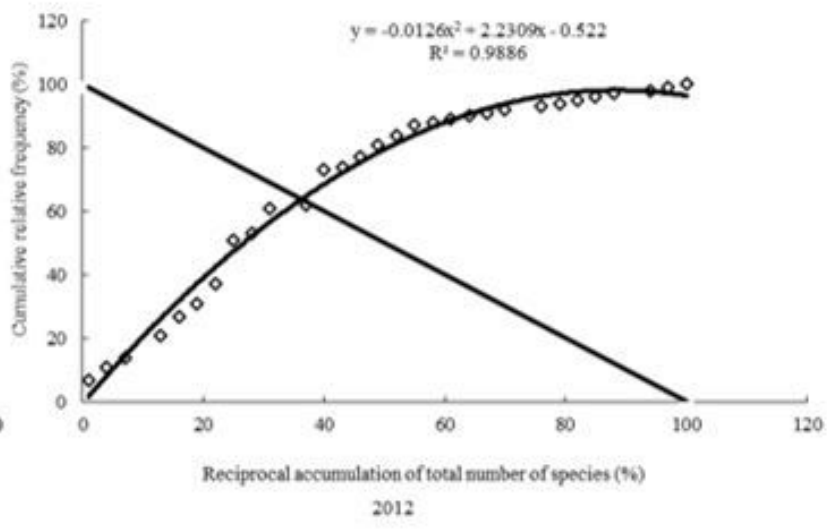

d

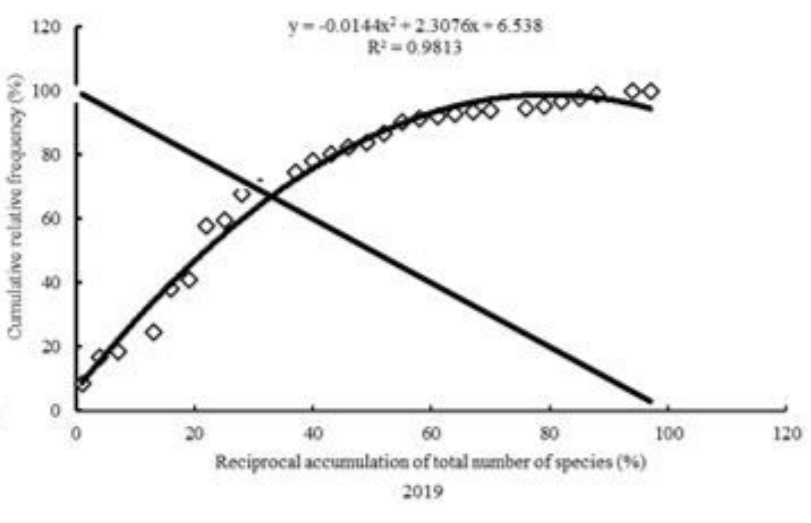

f 